\title{
An Approach to a Self-organizing Production in Comparison to a Centrally Planned Production
}

\author{
Torsten Munkelt*, Martin Krockert \\ Dresden University of Applied Sciences Faculty of Computer Science, \\ Friedrich-List-Platz 1, Dresden, 01069, GERMANY *torsten.munkelt@htw-dresden.de
}

SNE 30(1), 2020, 23 - 30, DOI: 10.11128/sne.30.tn.10506

Received: June 10, 2019 (Selected ASIM SST Hamburg 2018

Postconf. Publ.), Accepted: October 10, 2019

SNE - Simulation Notes Europe, ARGESIM Publisher Vienna

ISSN Print 2305-9974, Online 2306-0271, www.sne-journal.org

\begin{abstract}
Industry 4.0, a part of the German high tech strategy, prefers self-organization in production over central production planning for the sake of greater flexibility, faster response to disruptions and to deviations, and less effort. Current planning systems usually plan centrally. We developed a universal self-organizing production and empirically compared its performance to a centrally planned production. Compared to most other approaches, the self-organizing production does not just schedule already existing operations, but starts with material requirements, explodes the bills of materials, creates production orders, and schedules backwards. The self-organizing production is based upon agents. For better comprehensibility, we additionally implemented central planning. The results of self-organization in production are promising in relation to central planning; especially when disruptions and deviations occur. Furthermore, the results suggest as best solution a combination of rough central planning and self-organization.
\end{abstract}

\section{Introduction}

Current ERP, APS, and ME systems plan, control, and optimize production rather centrally. The systems provide "naive" resources with the following targets: when, what, where, how much, and by what means to purchase, to produce, to store, etc. Thereupon, the resources give feedback regarding time, quantity, and completion of production. According to the feedback, the above systems plan, control, and optimize anew after every shift or just every night; some are even able to react event-based but still plan centrally.
Industry 4.0 turns away from central planning, control, and optimization and promotes self-organization in production [1] which is expected to result in greater flexibility, in faster response to disruptions of the production and deviations in processing times, and in less computational effort. In this contribution, we confirm empirically that pure self-organization in production is possible. We compare a centrally planned and a selforganizing production empirically. Our experiments confirm that a self-organizing production performs as good as a centrally planned production [2] in most cases and often even better; especially when disruptions or deviations of processing times occur.

\section{Self-organization in Our Production}

Since self-organization is always an ability of a system, we initially define a system: A system is a set of components, which interact with each other and differ from the environment of the system [2]. There are many different definitions of self-organizing systems, e.g. "A self-organizing system is a system that changes its basic structure as a function of its experience and environment." [3] and "[A self-organizing system is a system in which] pattern formation occurs through interactions internal to the system, without intervention by external directing influences." [4].

In literature, the following properties are attributed to self-organizing systems $[5,4,6]$. Those properties may not be mutually exclusive and collectively exhaustive:

1. Openness: The system exchanges matter, energy, or information with its environment, and the exchange is the cause of the development of the system.

2. Adaptiveness: The systems adapts to changes in its environment.

3. Autonomy: The system and its components process all (external) stimuli from the environment according to internal mechanisms. 
4. Nonlinearity: The output of the system does not always change proportionally to its input.

5. Indeterminism: The system develops in a way, which is hard to predict because it depends on random events, or almost equal inputs lead to completely different paths of development.

6. Attraction: Over time, the system converges asymptotically to a region (a socalled attractor) in the state space of the system, and if the environment disturbs the system only slightly, the system will stay near the region.

7. Path dependence/operational closedness: The history (path of development) of the system influences the further development of the system much more than the environment of the system does.

8. Emergence: The system develops new spatiotemporal characteristics or structures as result of the interaction of its components. Those new characteristics and structures cannot be explained by the rather simple behavior of the single components.

9. Autopoiesis: The system or its components can autonomously create the components of the system. Hence the systems preserves itself.

According to the above definitions, properties 1, 2, 3, 7 and 8 are essential for a self-organizing system. Thus, if a system exhibits these properties, we will call it a selforganizing system. A production is a system, which produces goods [7]. If the production is also a selforganizing system, then it is a self-organizing production (system). Productions often also exhibit property 5 . Because of property 5 , analytical methods often fail to analyze productions successfully. Hence, we analyze our production by means of discrete-event simulation.

Self-organization in production is a central topic of Industry 4.0. The German government introduced Industry 4.0 as part of its high-tech strategy in 2011 [8]. Industry 4.0 describes the tight interlinkage between industrial production and modern information and communication technology [10]. Industry 4.0 is supposed to enable self-organizing production. Industry 4.0 comprises "intelligent" resources and "intelligent" materials. Resources are humans, machines, means of transportation, and storage systems. Materials are raw materials, purchase parts, assembly groups as well as final products. Resources and materials communicate and cooperate directly and locally and should thereby self-organize the complete value-added network.
Communication and cooperation span all phases of the product lifecycle. Concepts, programs, or platforms similar to Industry 4.0 are US-American "Smart Manufacturing", "Advanced Manufacturing", or "Industrial Value-Chain Initiative" [9], or the Chinese "Made in China 2015".

Production planning, control, and optimization already successfully applied self-organizing systems like self-organizing maps, artificial ant colonies [10], artificial neural networks [11], and genetic algorithms. However the combination of self-organizing production and Industry 4.0 leads to intelligent autonomous behaviour of machines and material, their communication, distributed computation, and in the end to multi-agent systems (MAS). For a definition of MAS and its agents, we refer to the Foundation for Intelligent Physical Agents [14]. There are three possible relationships between the agents on one side and the "intelligent" resources and materials on the other: Resources and materials are (two types of) agents, or agents connect to resources and materials physically, or agents are digital twins [12] of resources and materials. In the latter two cases, the agents make resources and materials "intelligent". In either case, the agents communicate and collaborate. Thus, the production organizes itself. Additionally, our MAS exhibits property 9: The MAS and its agents can autonomously create its agents.

\section{A Giffler-Thompson-based Resource Planning to Challenge the Self-organized Productions}

We implemented our own central production planning in order to compare a self-organizing production and centrally planned production fairly and comprehensibly. We adopted and stripped data structures and algorithms from current ERP systems, like SAP, as far as possible.

Our algorithm for central planning adapts well known scheduling and planning algorithms. It works as follows: In the first phase, the algorithm creates recursively the network of requirements and satisfiers via bill of materials explosion. Requirements are positions of customer orders, positions of production orders, or stock requirements. Satisfiers are positions of purchase orders, positions of production orders, or stock. They satisfy the requirements. 
The algorithm starts with requirements, which are not yet satisfied. During the same phase, the algorithm merges and splits lots according to fixed lot sizes and it schedules the network backwards, starting at their due time. If at least one satisfier starts in the past, the algorithm will execute phase two and phase three: In the second phase, the algorithm schedules the network forwards. It begins with the satisfiers, which start in the past and have no predecessors. In phase three, the algorithm schedules the network backwards again. It starts at the maximum of two points in time: the due time or the end time calculated by forwards scheduling. Phase three of the algorithm guarantees that the satisfiers start as late as possible. Phase four of the central planning executes finite capacity planning. It adapts the algorithm of Giffler and Thompson [13], considers earliest start times additionally, and schedules first the operation of that production order with shortest remaining slack time. Our central planning deliberately omits the phases of infinite capacity demand planning and capacity levelling because existing planning systems also do not automate these steps. Instead, we adjusted the parameters manually to guarantee a high and steady capacity utilization. Our central production planning operates periodically. When it starts anew, it changes remaining processing times and quantities according to the feedback from the production. Moreover, every new planning run firstly discards all connections between requirements and their satisfiers and secondly creates new connections with respect to the current situation of the production.

\section{Our Production Created for the Comparison of Self- Organization and Central Planning}

In order to compare self-organization and central planning, we created a production (see Figure 1). It produces two products. The products are wooden toy trucks. The bill of material of each product is three levels deep and contains 30 materials. Each material is produced in up to three operations. The operations of one material can seize a machine more than once. The operations sum up to 20 per product. Transportation times are not yet considered, but can be represented by an additional operation assigned to the material.

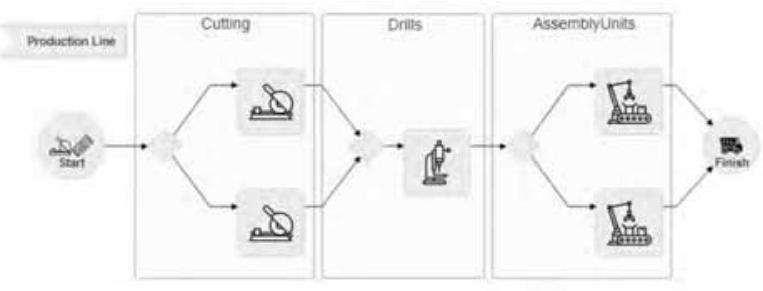

Figure 1: The main production flow involving two cutting machines, one drilling machine, and two assembly units. The production allows different routings for one product. The drilling machine is the bottleneck.

During the simulation of the production, new customer orders arrive at the production. The inter-arrival time of the orders is exponentially distributed as suggested in $[16,17]$. We choose an inter-arrival time, which leads to a well-utilized production but does not cause an overload. The production runs for two weeks, 24 hours a day. The production will produce approximately 35 products per day if the processing times do not deviate. To examine the flexibility of the production, we vary the processing times of the operations. According to [16] processing times are distributed log-normally. The inter-arrival times, the processing times, the capacity of the machines as well as the duration of the simulation can be configured separately for each simulation.

\section{Multi-agent-based Self- organization}

\subsection{Concept of a self-organizing production}

As defined in Chapter 2, a self-organizing production adapts to environmental changes. Although its components are able to build hierarchical structures, they interact as equals. Simulations of self-organizing systems commonly apply multi-agent systems [14]. The "intelligent" resources and material of Industry 4.0 also suggest a multi-agent-based approach to a self-organizing production. Hence, we also applied a multi-agent-based approach.

We defined eight different types of agents, which can be further divided into transient and persistent agents. The lifetime of transient agents starts and ends with their task. The lifetime of persistent agents starts and ends with the lifetime of the production. Figure 2 shows that all agents only know their direct neighbors. They are not aware of any other agent within the production. 


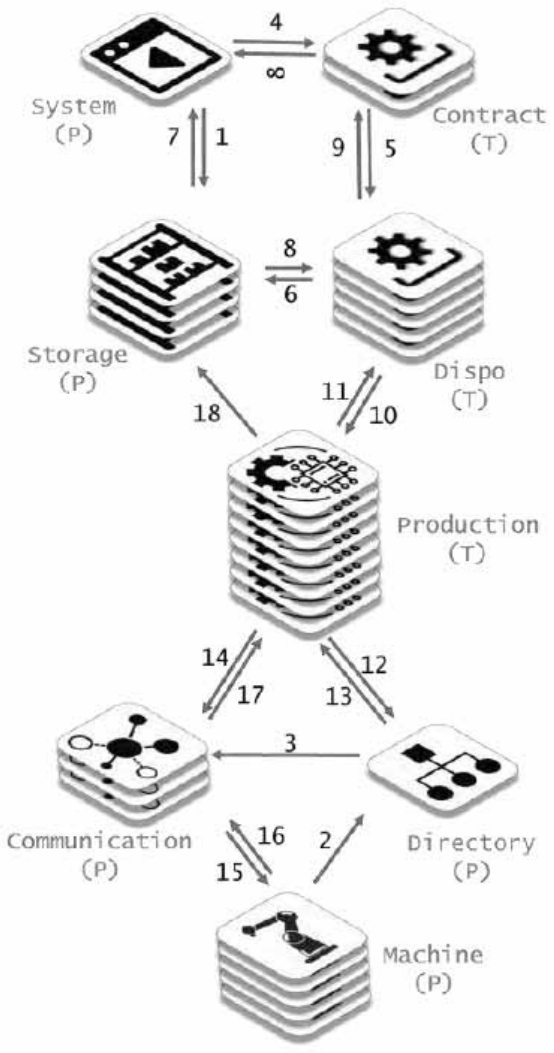

Figure 2: Concept of a multi-agent-based self-organizing production. Each symbol represents one type of agent. Each arrow is a communication path between two types of agents. In the text below, the numbers (\#number) refer to the communications paths. The letters in brackets describe the type of the agents according to their lifetime: $(\mathrm{P})$.. persistent and $(\mathrm{T})$.. transient.

Next, we explain the functionality of the multi-agentbased self-organizing production as well as the interactions between the agents. Therefore, we follow the processing of a single sales order throughout the production step by step.

\subsection{System initialization}

The MAS initializes the system, machine and directory agents during start-up and provides all required data, i.e. stock quantities to the storage agents (\#1), machine capabilities to the machine agents, etc. The agent initialized first during start-up, is the system agent, followed by the storage agents and the directory agent. The system agent is responsible for all in- and outbound communication of the MAS with its environment.
Second, the MAS creates all machine agents. The machine agents register at the directory agent and provide their capabilities (\#2). The directory agent creates and assigns a communication agent to each machine group (\#3) to provide a simple way of service discovery and to mediate between homogenous machines. Afterwards the production is ready to take orders and to start.

\subsection{Order processing}

If a new sales order arrives, the system agent will create a contract agent for this sales order (\#4). The contract agent supervises the order fulfillment. Therefore, the contract agent creates one dispo agent (\#5) for each product required to fulfill the order. The dispo agent represents a material in the real world: a digital twin. The dispo agent will ask the storage agent (\#6) if there is an equivalent product in stock at the time the sales order requires it. The storage agent will check if there is a product in stock or needs to be purchased by the system agent. (\#7). If the storage agent's response (\#8) to the request is positive, the dispo agent's task will be done and it will signal its parent agent, in this case the contract agent, that the task is finished (\#9). The contract agent signals the system agent that the contract is fulfilled $(\# \infty)$. If the storage agent's response is negative, the dispo agent will create a production agent for the required material (\#10). Then, the production agent instantiates new dispo agents for each of its components (\#11). The cycle will start again until the bill of material of the ordered product is fully processed. The contract agent does not ask the storage agent for available material directly but the newly created dispo agent does because the dispo agent has to ask for available material anyway when asked by a production agent. Thus, only one agent keeps the same functionality.

\subsection{Self-organizing scheduling with restricted horizon}

The task of each production agent is not only to order its components but also to organize all required operations to assemble its assembly group. All production agents are competing for the earliest production timeslot on a machine. Therefore, the production agent requests one communication agent for each of its operations from the directory agent (\#12). The directory agent returns the communication agent, which is responsible for the operation specified at the request (\#13). 
Afterwards, the production agent sends a "request for proposal" to the communication agent assigned to the operation (\#14), similar to the Contract Net Protocol [20]. The communication agent forwards each incoming request to all of its machine agents (\#15). Each machine agent calculates a possible start time based on the slack time of the operation and the current queue of the machine agent. That start time is returned as proposal by the machine agents (\#15) to the communication agent (\#16). After each machine agent returned a proposal to the communication agent, it decides for the proposal with the earliest start time and sends an acknowledgement to the assigned machine agent (\#15). Furthermore, the communication agent sends the assigned scheduling information to the requesting production agent (\#17).

The machine agent organizes the acknowledged proposals as operations in its own queue. Operations, which would not be processed for more than 60 minutes, are rejected with the prompt to try again after 45 minutes. Further analyses may address other time limits. If the machine agent receives an acknowledgement of an operation, this operation will be enqueued. Operations with a longer slack time than the previously enqueued operation are dropped from the queue, and the machine agent informs their communication agents to request new proposals for them (\#16). This way, another machine agent could respond with a better proposal.

After the machine processes a material, its machine agent sends a completion message to the communication agent (\#16). The communication agent forwards the message to the related production agent (\#17). The production agent receives the message and sets the status of the subsequent operation to ready, for machines are only allowed to process ready operations. If there is no subsequent operation, the production agent will assume that the material is fully processed and forward the completion message to the related dispo agent (\#11) which terminates itself because its task is done. The production agent also sends a message to the storage agent (\#18) and terminates itself because its task is also done. The storage agent provides the currently produced material to the requesting dispo agent (\#6) with the shortest slack time. After the dispo agent receives the required material, the production cycle starts over until the product is fully assembled.

\section{Results of the Empirical Comparison of a Self- organizing and a Centrally Planned Production}

\subsection{Parameters to vary}

The simulation applied the parameters specified in Table 1 . The production reached its steady state after approximately 24 hours. We added another 24 hours before we started the measurement of the KPIs. First, we chose a set of parameters both productions behaved well with: deviation of processing times $\pm 20 \%$, lot size 1 , planning scope $32 \mathrm{~h}$, planning horizon $24 \mathrm{~h}$, planning reset after $24 \mathrm{~h}$, and average time to delivery $72 \mathrm{~h}$. Applying these parameters, both productions had an average machine workload of $80 \%$ and delivered $100 \%$ of the sales orders in time. A major difference between the centrally planned and the self-organizing production was a significant deviation of lead times for both products. The centrally planned production had an average lead time of $4 \mathrm{~h}$ in contrast to the self-organizing production with an average lead time of $8 \mathrm{~h}$. This results from longer lay time between the operations which cause higher stock for all components (see Table 2).

The difference between the lay times and lead times of the centrally planned production and the selforganizing production leads back to two reasons: The self-organizing production starts as early as possible, and the Giffler-Thompson algorithm of the centrally planned production packs the operations tightly.

\begin{tabular}{ccccc}
\hline & Description & Type & \multicolumn{2}{c}{ Values } \\
\hline Deviation & $\begin{array}{c}\text { Time duration devia- } \\
\text { tion for operations }\end{array}$ & C/S & $0 / 20 / 40$ & $\%$ \\
\hline Lot-size & $\begin{array}{c}\text { Lot size for assembly } \\
\text { groups }\end{array}$ & C & $1 / 5 / 10$ & pcs. \\
\hline $\begin{array}{c}\text { Planning } \\
\text { scope }\end{array}$ & $\begin{array}{c}\text { Limit time up which } \\
\text { orders are taken } \\
\text { into account }\end{array}$ & C & $8 / 24 / 32$ & $\mathrm{~h}$ \\
\hline Planning & $\begin{array}{c}\text { Time for rescheduling } \\
\text { reset }\end{array}$ & $\mathrm{C}$ C all remaining and & $8 / 24$ & $\mathrm{~h}$ \\
\hline new orders & & & \\
\hline Order due & $\begin{array}{c}\text { Average time from or- } \\
\text { der placement to } \\
\text { delivery }\end{array}$ & $\mathrm{C} / \mathrm{S}$ & $48 / 72$ & $\mathrm{~h}$ \\
\hline
\end{tabular}

Table 1: Parameters, their descriptions, and their values for the initial simulation run, [C]entrally planned and [S]elf-organizing production. 


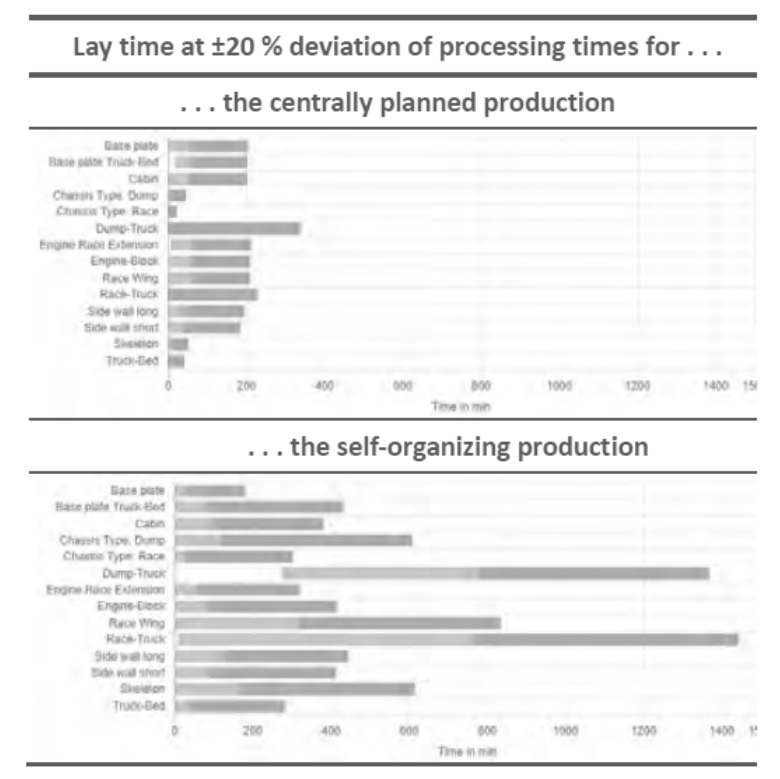

Table 2: Lay time range for each component. Green equals the lower half and red equals the upper half of the average lay time. The median lies at the transition from green to red.

\subsection{Shortening the time to delivery}

We shortened the time to delivery, to examine the performance of both productions under stress. Therefore, we ran the simulation with $\pm 20 \%$ deviation, lot size 1 , planning scope and reset after $24 \mathrm{~h}$, and in average $48 \mathrm{~h}$ to delivery. Again, both productions reached a similar average machine workload of $80 \%$. The lead time for the products increased moderately by about $\pm 20 \%$. But the centrally planned production only delivered $14 \%$ of the products in time. In contrast, the self-organizing production was able to adapt and delivered $100 \%$ of the products in time. Table 3 shows the results of the simulation and visualizes that the self-organizing production was not only able to produce everything in time, but also produced 41 more end products during the analyzed period of time.

We tried to increase the timeliness of the centrally planned production. For this purpose, we tested fixed lot sizes with 5 and 10 pieces; but the timeliness increased only marginally. In further tests, we allowed the centrally planned production to plan anew every 8 hours but the timeliness did not improve either, because new customer orders enter the system more often and processing times deviate all the time. This leads us to the conclusion that our central planning is not able to cope with shorter times to delivery. That is why we will apply professional planning systems for further comparison.

\begin{tabular}{lcc}
\hline Parameter & \multicolumn{2}{c}{ Values } \\
\hline Simulation Type & $\begin{array}{l}\text { centrally } \\
\text { planned }\end{array}$ & self-organizing \\
\hline total timeliness in [\%] & $18 \%$ & $100 \%$ \\
\hline Quantity in [pcs.] & 385 & 423 \\
\hline $\begin{array}{l}\text { Max/Min deviation from } \\
\text { delivery time in [min] }\end{array}$ & $-320 / 385$ & $-1431 /-7$ \\
\hline
\end{tabular}

Table 3: Product timeliness with $\pm 20 \%$ deviation and an average of 48 hours to delivery for all orders.

We tried to increase the timeliness of the centrally planned production. For this purpose, we tested fixed lot sizes with 5 and 10 pieces; but the timeliness increased only marginally. In further tests, we allowed the centrally planned production to plan anew every 8 hours but the timeliness did not improve either, because new customer orders enter the system more often and processing times deviate all the time. This leads us to the conclusion that our central planning is not able to cope with shorter times to delivery. That is why we will apply professional planning systems for further comparison.

\subsection{Varying the deviation of processing times of operations}

Many disruptions and deviations may occur during the manufacturing of a product. Machines may break down, products may be rejected because of quality issues, personnel may drop out, operations may take more or less time than originally planned, etc. All these disruptions and deviations lead to deviating processing times of operations. We varied the duration of processing times of operations randomly by $\pm 20 \%$ and $\pm 40 \%$ to examine the influence of the variations on the KPIs. The self-organizing production was able to handle both. It handled $\pm 20 \%$ deviation with ease, and even at $\pm 40 \%$ deviation, it delivered $94 \%$ of all incoming sales orders in time. The centrally planned production performed even worse than expected: At $\pm 20 \%$ deviation, the centrally planned production reached $14 \%$ timeliness only, and at $\pm 40 \%$ deviation, it was not able to finish any product in time. Due to the high deviation of processing times and the rather long time between two consecutive central planning runs, the average lead times grew from $200 \mathrm{~min}$ (at $\pm 20 \%$ deviation) up to $3000 \mathrm{~min}$ (at $\pm 40 \%$ deviation). In contrast, the selforganizing production had a maximum of average lead time of $1100 \mathrm{~min}$ (see Table 4). 


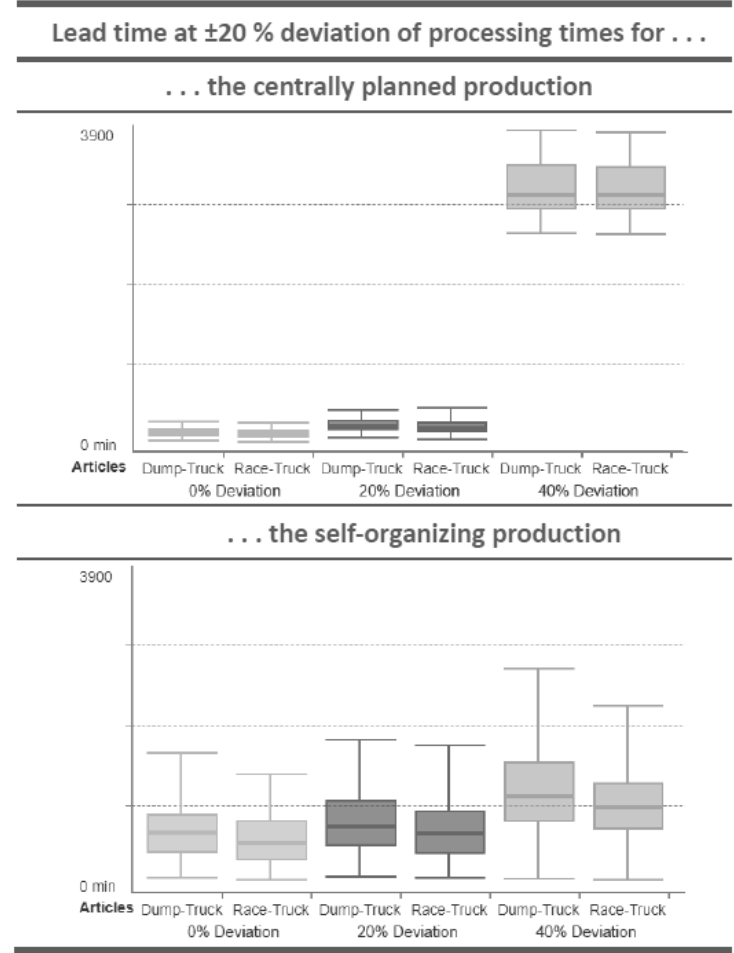

Table 4: Lead time comparison from left to right with $0 \%, \pm 20 \%$, and $\pm 40 \%$ deviation of processing times.

To reduce the lead times in the self-organized production, we delayed the production start like it is common [23]. Only when the time remaining until due time was equal to the upper fence [24] of the previous lead times, the production started. The deviation of the processing times of the operations stayed at $\pm 20 \%$. The delay led to lead times almost equal to the lead times achieved by the centrally planned production (see Table 5 ). Furthermore, the delayed start of the production reduced overall stock in the self-organizing production to values even lower than in the centrally planned production (see Table 6). Despite the delayed start of the production, the self-organizing production still completed all orders in time.

Table 5 also shows quartiles of the lead times of the self-organizing production. These quartiles are more than twice as wide as the quartiles of the lead times of the centrally planned production. To narrow the quartiles of the lead times of the self-organizing production, we will investigate how different priority rules and loaddependent start times influence lay times, lead times, and stock. In order to achieve even better results, we will combine rough central planning and our selforganizing production.

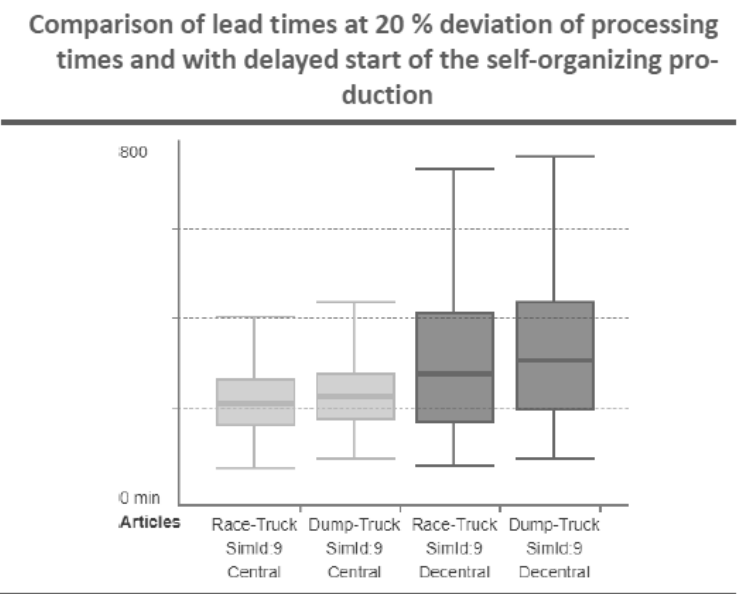

Table 5: Lead time comparison $([1,2]$ centrally planned production; [3, 4] self-organizing production).

Comparison of stock evolution at $\mathbf{2 0} \%$ deviation of processing times for...

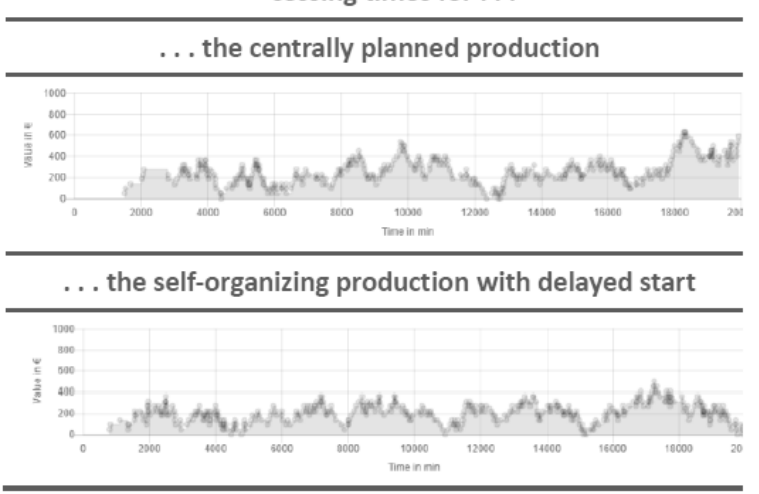

Table 6: Stock values over time in comparison.

\section{Conclusion and Outlook}

The target of our research was to develop a concept for a self-organizing production and prove the concept empirically. We developed the concept and a prototype of a self-organizing production. We let the prototype compete with a widely used and well-established algorithm for central production planning. We simulated a self-organizing and a centrally planned production with the same presets of random data and were able to prove the viability of the self-organizing production under the given circumstances. The results show that a selforganizing production is extremely robust against disruptions and deviations during physical production. While the centrally planned production stuck with its originally created plan, the self-organizing production timely adapted to deviations in processing times. 
The tradeoff were longer lay times, longer lead times, and higher stock.

Next, we will incorporate set-up times and dynamic lot-sizing in our production.

\section{References}

[1] Lasi H. Industrie 4.0,“ Wirtschaftsinformatik, pp. 261264, 04042014

[2] Scholz-Reiter B, Görges M, Philip T. „Autonomously controlled production systems-Influence of autonomous, “ in CIRP Annals -Manufacturing Technology, Bremen, 2009.

[3] Buckley WF, Society - a Complex Adaptive System: Essays in Social Theory, Amsterdam: Gordon and Breach, 1998.

[4] Clark W, Farley B. ,Simulation of self-organizing systems by digital computer, “ Transactions of the IRE Professional Group on Information Theory, Bd. 4, Nr. 4, p. 8, 1954.

[5] Camazine S, Deneubourg JL, Franks NR, Sneyd J, Guy T, Eric B. Self-Organization in Biological Systems, Woodstock: Princton University Press, 2003.

[6] Köhler-Bußmeier M. „Koordinierte Selbstorganisation und selbstorganisierte Koordination,“ Hamburg, 2010.

[7] Kauffman S. At Home in the Universe: The Search for the Laws of Self-Organization and Complexity, Oxford : Oxford University Press, 1996.

[8] Schuh G. Produktionsplanung und -steuerung, Aachen: Springer Verlag, 2006.

[9] Kagermann PDH, Wahlster PDW, Helbig DJ. „Umsetzungsempfehlungen für das Zukunftsprojekt Industrie 4.0,“"Frankfurt/Main, 2013.

[10] Bauernhansl T, Hompel MT. Industrie 4.0 in Produktion, Automatisierung und Logistik, Wiesbaden: Springer, 2014.

[11] Anderl R, Dumitrescu R, Eigner M, Ganz C, Huber AS, Michels JS, Rückert T, Tian S, Stark R, Zhi P. Industrie 4.0 genzenlos, U. Sendler, Hrsg., Heidelberg: Springer Vieweg, 2016.

[12] Klüver C, Klüver J, Jörn S. Modellierung Komplexer Prozesse durch naturanaloge Verfahren, 2 Hrsg., Wiesbaden: Spinger Verlag, 2012.

[13] Hammami Z, Mouelhi W, Said LB. ,A self-adaptive neural-agent-based decision support system for solving dynamic, " in Intelligent Systems and Knowledge Engineering, Tunis, 2015.

[14] Poslad S. „Specifying protocols for multi-agent systems interaction, " in ACM Transactions on Autonomous and Adaptive Systems, New York, 2007.
[15] Grieves DM. „Florida Institute of Technologie,“ 2014. [Online]. Available:

http://innovate.fit.edu/plm/documents/doc_mgr/9 12/1411.0_Digital_Twin_White_Paper_Dr_Griev es.pdf.

[16] Zäpfel G, Braune R. Moderne Heuristiken der Produktionsplanung, München: Vahlen, 2005.

[17] Košturiak J, Gregor M. Simulation von Produktionssystemen, Wien : Springer Verlag, 1995.

[18] Bronstein IN, Semendjajew KA, Gerhard M, Mühlig H. Taschenbuch der Mathematik, Frankfurt am Main: Harri Deutsch, 2016.

[19] Völker S. Reduktion von Simulationsmodellen zur simulationsbasierten Optimierung in der Termin- und Kapazitätsplanung, Frankfurt am Main: Peter Lang Verlag, 2003.

[20] Jonathan MEG, Hujun Y, Wright WA, Allinson NM. „Self-Organization, Emergence and Multi-Agent Systems, " in Neural Networks and Brain, 2005. ICNN\&B '05. International Conference onVolume: 3, Beijing, 2005.

[21] Ried S. „The Contract Net Protocol: High-Level Communication and Control in a Distributed Problem Solver," in Transaction on computers, Vol. C29 No 12, 1980.

[22] Corsten H, Gössinger R. Produktionswirtschaft, 13. Hrsg., München: Oldenbourg-Verlag, 2012.

[23] Mendenhall W, Beaver RJ, Beaver BM. Introduction to Probability and Statistics, Belmont, CA, USA: Cengage Learning, 2008.

[24] Dilger W. „Multiagentensysteme,“ Chemnitz , 2005.

[25] Hewitt C. ,A universal modular ACTOR formalism for artificial intelligence, " in IJCAI'73 Proceedings of the 3rd international joint conference on Artificial intelligence, Stanford, 1973.

[26] Kirmse P. „Platform Industrie 4.0,“ 2017. [Online]. Available: http://www.plattformi40.de/I40/Redaktion/DE/Anwendungsbeispiele/137wandelbare-r8-manufaktur/beitrag-wandelbare-r8manufaktur.html. [Zugriff am 1911 2017].

[27] Roth A. Einführung und Umsetzung von Industrie 4.0, Heidelberg: Springer Gabler, 2016.

[28] Soder J. Handbuch Industrie 4.0, 2 Hrsg., Bd. 1, B.Vogel-Heuser, T. Bauernhansl und M. ten Hompel, Hrsg., Springer, 2017.

[29] Schukraft S, Grundstein S, Scholz-Reiter B, Michael F. „Evaluation Approach for the Identification of Promising Methods to Couple Central Planning and Autonomous Control, “ in International Journal of Computer Integrated Manufacturing, 2015. 